\title{
Trust in Management under Post-bureaucratic Conditions: The Case of Finnish Civil Servants
}

\author{
Jaakko Koivumäki \\ Labour Market Researcher, Finnish Dental Association \\ jaakko.koivumaki@hammaslaakariliitto.fi \\ Pasi Pyöriä \\ University of Tampere \\ pasi.pyoria@uta.fi
}

\begin{abstract}
The Finnish state administration has recently undergone a wave of reforms towards decentralized decision-making and increased flexibility in organizing work. Traditional bureaucracy, however, has its virtues. Based on a survey and qualitative interview material, the results presented in this paper indicate that many characteristics of bureaucracy, such as well-defined work roles and hierarchical control, facilitate trust among employees. In contrast, the current post-bureaucratic model of organizing work may increase insecurity and decrease trust.
\end{abstract}

Keywords: Bureaucracy, Public sector, Trust, State administration, Finland.

Confianza en la gestión bajo condiciones posburocráticas: el caso de los funcionarios públicos finlandeses

Resumen: La administración del Estado finlandés ha sido objeto recientemente de una ola de reformas hacia la toma de decisiones descentralizada y una mayor flexibilidad en la organización del trabajo. No obstante, la burocracia tradicional tiene sus virtudes. Basados en una encuesta y material de entrevista cualitativo, los resultados presentados en este trabajo indican que muchas de las características de la burocracia, como los roles de trabajo bien definidos y el control jerárquico, facilitan la confianza entre los empleados. Por el contrario, el modelo posburocrático actual de la organización del trabajo puede aumentar la inseguridad y disminuir la confianza.

Palabras clave: burocracia, sector público, confianza, administración del Estado, Finlandia. 


\section{Introduction}

Over the past few decades there has been a wave of public sector reforms in the OECD countries. New managerial practices, many of them adopted from the private sector, have shaped the structures and practices of public sector organizations (Hood, 1996; OECD, 2000; Pollitt and Bouckaert, 2004).

Most of the reforms have been designed to decentralize decision-making from central administration (ministries) to single agencies (offices, institutes), with a view to increasing flexibility in organizing work and developing a stronger customer orientation. Finland, the case highlighted in this paper, has in this respect followed the lead of other industrialized countries (see also Temmes, 1998; Tiili, 2008).

In Finland this development has been faster than in most other countries. Until recently the basic structures of Finnish public administration were relatively stable. After the economic recession of the early 1990s, a wave of reforms swept the country. Consequently, many of the reforms that were initiated in the 1990s (e.g. performance-based pay systems for civil servants) were completed by the millennium.

Interestingly, these changes coincided with Finland's growing international reputation as one of the most competitive information societies in the world (Blom et alii, 2002; Pyöriä, 2007b; Schienstock, 2007). The quest for competitiveness comes at a price, though. Although Finland can still be regarded as a Nordic welfare state, social inequality and income differentials have been on the increase since the mid-1990s (OECD, 2010).

In contrast to the trend of decentralization in decision-making, economic power in Finnish state administration is increasingly centralized. The concentration of economic power stems from aspirations to improve cost efficiency in the public sector. This drive to optimize the use of scarce resources has led to the introduction of new managerial principles, such as management by results and total quality management (TQM).

In parallel with ongoing public sector reforms, there has been a growing interest in intangible assets, such as social capital and trust. It is argued that in an information society, successful work organizations must be innovative and flexible in order to survive. Both private and public sector organizations should discard formal control mechanisms and hierarchies and replace them with trustbased, horizontal coordination (Adler, 2001; Bijlsma-Frankema and Costa, 2005; Nahapiet and Ghoshal, 1998).

According to this line of argument, post-bureaucratic forms of work organization constitute a new frontier of control. When rigid hierarchies 
are discarded, employees tend to internalize the same values and goals as management. However, the abandonment of bureaucratic control is not always welcomed. Among employees it may heighten feelings of suspicion and create opposition (Wittek and van de Bunt, 2004).

Are these two trajectories - the emergence of post-bureaucratic managerial principles and the importance given to trust - mutually compatible? Do postbureaucratic organizations engender a sense of trust in the public sector context?

In this article these questions are addressed from the point of view of individual employees in the service of Finnish state administration. Our aim is to explore factors related to civil servants' trust in their supervisors under postbureaucratic conditions. The analysis draws on survey data $(n=440)$ collected from five organizations.

The article is organized as follows: First, we begin with a description of the shift from bureaucracy to a post-bureaucratic regime; second, we define and explore the concept of trust; third, we introduce the survey material; fourth, we present the results in three sub-sections; and fifth and finally, we provide a short summary and discussion.

Despite the critical tone of this article, it is not our intention to lay the blame for the problems in Finnish state administration upon practicing managers. Managers work under considerable pressure and are victims of the system in the same way as their subordinates are.

\section{Post-bureaucracy}

Just a short few decades ago, bureaucracy was widely considered the ideal model for organizing work in the public sector. Since the late 1970s, however, it has turned into a virtual enemy for political and administrative elites. As du Gay (2000) puts it, if «entrepreneurial governance» has one overarching target - that which it most explicitly defines itself in opposition to - then it is the impersonal, procedural, hierarchical and technical organization of the Weberian bureau' (p.6).

According to Max Weber (1978, pp. 956-958), an efficient bureaucracy is built upon a stable distribution of authority that is strictly delimited by rules. In Weber's view a bureaucracy based on rational-legal authority is reliable for both superiors and subordinates, because subordinates can always challenge the decisions made by management if formal rules are broken. Thus, one of the chief virtues of a bureaucracy is predictability.

However, what once was a virtue has now become a vice. Instead of predictability and clear hierarchies, today's organizations are expected to demonstrate flexibility. Post-bureaucratic organizations - defined by Heckscher 
and Donnellon (1994) as 'cleaned up bureaucracies' - are seen as a means of achieving savings in public expenditure, improving the quality of public services, enhancing the efficiency of government, and increasing the chances that chosen policies are effective (Pollitt and Bouckaert, 2004).

In a post-bureaucratic environment, public sector professionals are made accountable not only to their direct supervisors but also to government, funding bodies and clients. According to Alvesson and Thompson (2004), the price paid for this shift has been a growth in centralized audit monitoring, with a consequent decline in trust and collegiality. Dingwall and Strangleman (2004) go even further and say that this has often led to outright cynicism - a kind of laissez faire organizational culture which may have a demoralizing impact on wider legal and political cultures surrounding public sector organizations. Bureaucratic rationality has indeed been replaced by market rationality.

To understand individual reactions to these changes it is useful to turn to the concept of psychological contract (Rousseau, 1995). The psychological contract refers to an employee's perception of what they owe the employer and what the employer owes them. The norm of reciprocity is the basic social mechanism underlying the contract. Traditionally, as Weber (1978) observed, civil servants have traded loyalty for a secure career: 'entrance into an office $(. .$.$) is considered$ an acceptance of a specific duty of fealty to the purpose of the office in return for the grant of a secure existence' (p. 959).

However, if an employee feels that the contractual obligations are not met, then their trust in the employer will probably be eroded. Importantly, this may also spill over to affect the employee's trust in upper management and organizational commitment. The spillover effect is greater if the unfair act is interpreted as intentional - particularly if nothing is done to remedy the situation (Den Hartog, 2003).

Although the empirical evidence remains mixed and varies from country to country, it is safe to say that amidst the recent tumultuous public sector reforms , civil servants' expectations have been breached. In the context of Finland, this is seen in the fact that temporary employment contracts, for example, are twice as common in the public sector as in private enterprises. In 2008 over $20 \%$ of Finnish public sector workers had a fixed-term contract, whereas in the private sector the corresponding figure was $8 \%$ (Lehto and Sutela, 2009).

There may be no need to add that bureaucratic and post-bureaucratic forms of organizations are Weberian ideal-types, rather than empirically accurate descriptions or mirrors of reality. There are differences between public sector organizations (see, e.g., Naschold 1996), but these differences are beyond the 
scope of this article. Suffice it to say here that bureaucracy is an adequate concept for the purpose of the present analysis.

\section{Trust}

It is often argued that while knowledge has become increasingly important for the economy, it has made institutions dependent on trust. According to Adler (2001), economic and organizational theory has shown that, in comparison to trust, the two conventional mechanisms of coordination, market/price and hierarchy/ authority, are relatively ineffective means of dealing with knowledge assets. Adler therefore emphasizes the role of trust as a mechanism of coordination: it helps reduce transaction costs by replacing formal contracts with informal networking (ibidem, p. 219).

There are many other positive consequences of trust. According to BijlsmaFrankema and Costa (2005), empirical studies support the theoretical idea that trust lubricates relations between partners and organizational processes by promoting a variety of voluntary behaviours that enhance trust-building and performance. These include psychological security, belief in information and acceptance of influence, mutual learning, attribution of positive motives, and positive outcomes such as high levels of cooperation and performance.

Because of its inherent complexity and its situation-specific characteristics, the concept of trust has been defined in many different ways (Blomqvist, 1997). On a general level, trust can be defined as a belief that a person who is trusted will behave according to expectations, and, respectively, that they will not take advantage of the person who trusts them, even if there is the possibility for opportunistic behavior (Cummings and Bromiley, 1996). Since trust is directed towards the future, the possibility of betrayal is always present.

According to Lewis and Weigert (1985), trust has cognitive, emotional and behavioral aspects, which are connected in social reality. We carefully consider who and how to trust and in what circumstances. We connect emotionally to one another and, therefore, a betrayal causes emotional pain to both parties. We also constantly need to trust different kinds of people and institutions - even those we encounter for the first time.

Nooteboom (2002, p. 10) suggests that to create a more systematic conceptualization of trust, we should distinguish between:

+ What can we have trust in? Things, people, institutions, organizations?

- What are the relations between these different levels of trust?

- What are aspects of trust: competence, intentions, and what else? 
It is also important to notice the dynamic nature of trust. As many authors have noted, trust is not a static phenomenon but can increase and decrease, as social and economic exchange is in constant flux. Fox (1974) emphasizes that both trust and distrust usually feed themselves. In a similar vein, Blau (1964) suggests that social exchange requires others to be trusted to discharge their obligations and generates trust by expanding the cycle of mutual exchange of services. In more practical terms, empirical studies drawing on social exchange theory have shown that employees trust management more when they are allowed to participate in decision-making and decide about their own work (Deci et alii, 1989).

Although trust is a powerful mechanism in coordinating group behavior, exclusive reliance on trust has certain limitations and costs, as does every organizational structure (Coleman, 1990; Groth, 1999). However, in favorable conditions trust provides the strongest possible foundation for fruitful collaboration in small groups, such as in teams of professionals working on a joint project (Pyöriä 2007a). The more time is invested in building trust, the more the investment will pay back in terms of higher morale and efficiency. As the shared context of understanding among team members grows deeper, the easier it becomes to communicate complex ideas and avoid useless interaction.

\section{Research setting and material}

The research setting of this study differs from the typical hypothetico-deductive model often suggested in quantitative methodology. In survey research the theoretical framework is usually reasonably narrow and the few hypotheses derived from it are tested and evaluated. Unlike this tradition, a fundamental goal here is not to test hypotheses but to increase holistic understanding of micro organizational contexts and mechanisms in and by which trust might develop or break under conditions of organizational change.

Of course, the research setting used here is deductive inasmuch as there is a theoretical framework in which the results will be reflected. However, empirical analysis follows the logic of inductive/explorative research, which is more common in qualitative than quantitative studies (see, e.g., Yin, 1989). Empirical exploration (motivated by curiosity) - with 'sociological imagination' (Bauman, 1990; Mills, 1959) thrown in for good measure - is the key principle in the chosen methodology. The epistemological basis of this approach rests on the philosophical tradition of pragmatism. Pragmatism stands for ontological tolerance and emphasizes that research questions should define methods and 
not vice versa (cf. Chicago school; see also Atkinson and Housley, 2003, 1-26; Bryman, 1992; Tashakkori and Teddlie, 1998).

The survey data $(\mathrm{n}=440)$ for this study were collected from five state administration organizations in Finland. The main criterion for selecting the organizations was that they should constitute a 'sample' that adequately represents knowledge-intensive public sector organizations that employ civil servants in advisory positions. In the selection process, experts from the Finnish State Employer's Office were consulted. They were informed of the purpose of the study and then asked to name examples of appropriate research objects.

The consultation immediately showed that employees' experiences (e.g., insecurity in its many forms) as well as the level of trust were very similar in different organizations. Organization explained only $3 \%$ of the variance in trust whereas, for example, work group / team explained $26 \%$. This result strongly indicates that variance in trust within the organizations is significantly higher than between the organizations. Therefore, it was well-grounded to put the respondents (employees from the different organizations) in the same pool and not to compare organizations.

Two of the five cases (B and $\mathrm{D}$ ) can be classified as research organizations, while the other three are more or less traditional expert bureaucracies. Organization A is local, and the others national. A brief description of each organization is presented below.

Organization $A$ is a regional environmental agency whose core function is to supervise environmental protection, land use, construction and the use and management of local water resources. Organization $B$ produces and disseminates scientific research and develops and promotes the transfer of new technology to the agriculture and food sector. Organization $C$ serves the state as a financial and personnel administration expert, providing guidance on the production of administrative information and the use of procedures in administration, and by directing the use of purchased services. Organization $D$ is a research organization that provides high-end technology solutions and innovation services for the public and private sector. Finally, organization $E$ is responsible for two broad government sectors: transport policy and communications policy.

A questionnaire was mailed to all employees not occupying managerial positions in these organizations (between 29 March 2006 and 19 May 2006). Questionnaires were completed by 440 employees, resulting in a response rate of $46.5 \%{ }^{1}$ No significant differences were found between the sample and

1 Organization A: response rate $65 \% / n=75$; Organization B: response rate $46 \% / n=151$; Organization C: response rate $50 \% / n=78$; Organization D: response rate $46 \% / n=88$; Organization E: response rate $31 \% / \mathrm{n}=48$. 
population for type of employment contract (permanent vs. contingent), gender, age or occupational/educational group. Survey respondents were also encouraged to give feedback after completing the questionnaire. Many took advantage of this opportunity.

Comparisons of the responses (distributions and means) to some key variables, such as trust in management and perceived insecurity factors (threats) at work, indicate that civil servants have very similar experiences across different Finnish state administration organizations. This was expected a priori because of the heavily centralized strategy of public management reforms in Finland (cf. Pollitt and Bouckaert, 2004; Tiili, 2008).

\section{Results}

This section is organized into three themes. First, it describes the organizational environment of the work communities studied and explores recent changes in the nature of work. It then moves on to define the measure of trust in the supervisor, and finally traces the antecedents of trust.

\subsection{The contradictory work situation of Finnish civil servants}

Richard Sennett $(1998 ; 2006)$ and other social critics argue that the decline in bureaucracy has created shared experiences of insecurity among employees across all branches of the economy. Inspired by Sennett's ideas, we formulated some survey items to measure perceived insecurity in relation to respondents' work and employment situation. The insecurity factors illustrated in Figure 1 are interpreted as reflecting confidence in the employer/employment, on the one hand, and a sense of psychological control (Fiske and Taylor, 1984), on the other.

Figure 1. Number of employees who perceive threats to their work (\%)

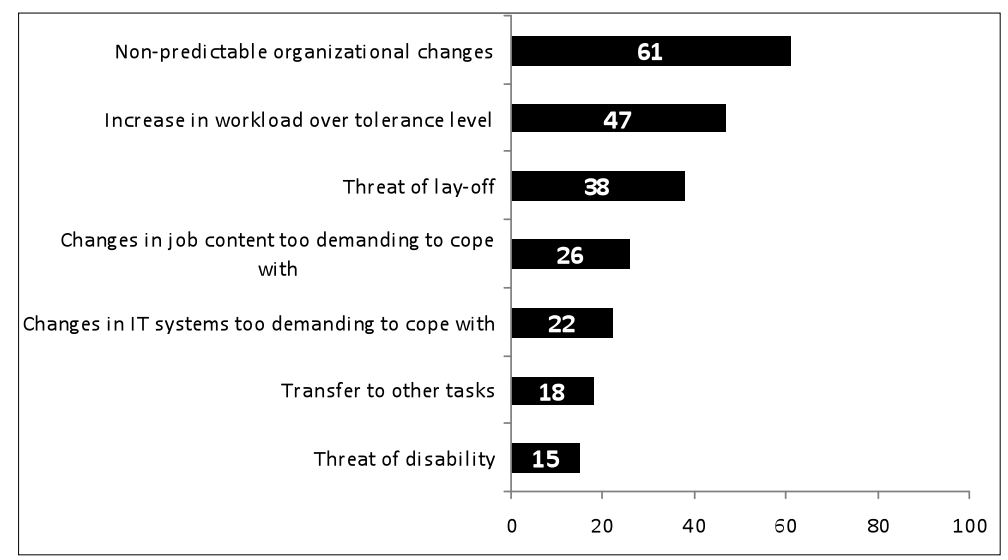


As many as $61 \%$ of the respondents perceive unpredictable organizational changes as a threat to their work. This reflects low confidence in upper management and severe problems in vertical communication. Low employee confidence in the employer and in employment prospects is also reflected in the responses of those $38 \%$ who perceive a threat of lay-offs. This figure is surprisingly high in view of the fact that real layoffs in Finnish state administration have been very rare. Perhaps the result is an indication of what is expected to happen in the near future - possibly in the next phase of organizational reform. Almost half of the respondents also fear that their workload may increase to exceed their tolerance level.

Let us examine the perceived changes related to the nature of work. As illustrated in Figure 2, employees were asked to evaluate retrospectively how, if at all, their job had changed in recent years.

Figure 2. Perceived changes in the nature of work in recent years (\%)

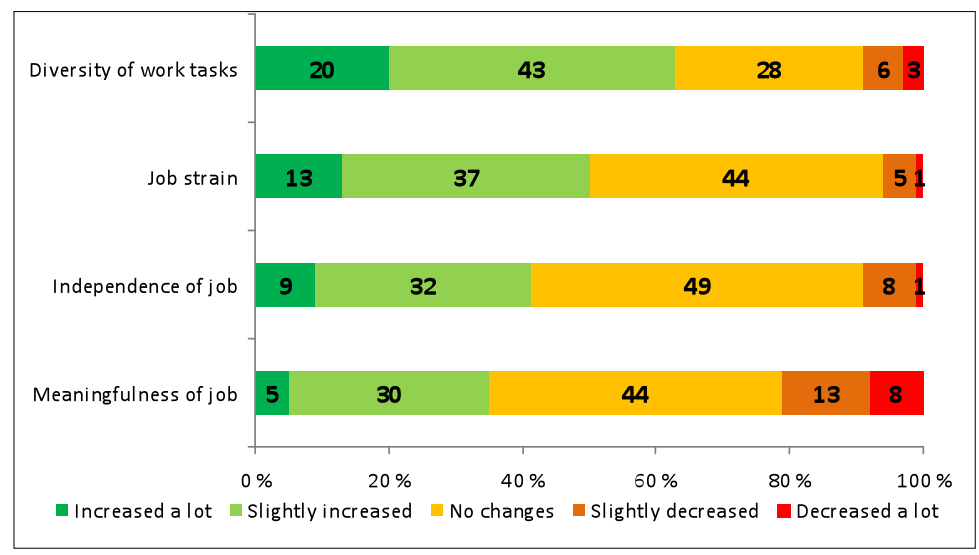

In general, it seems there have been more positive changes than negative ones. A total of $41 \%$ of the respondents feel that they have greater independence on the job, while almost half perceive no changes; $35 \%$ perceive an increased meaningfulness of work (44\% perceives no changes); and a high $63 \%$ feel that the diversity of their work tasks has increased (28\% perceive no change). At the same time, however, half of the respondents feel that levels of job strain have also increased, whereas only $13 \%$ feel there is less strain on the job. This seeming paradox whereby an increased sense of job meaningfulness coincides with increasing levels of strain can be explained by the assumption that experiences of job strain are influenced not so much by the nature of work, but more by the environment in which the job is done. 
To sum up, it seems that the conflicting trends towards operational decentralization, on the one hand, and strategic centralization, on the other, indeed add up to contradictions that are reflected in individual attitudes (cf. Sennett, 1998, pp. 55-57). It seems evident that people's sense of insecurity has increased, even though they feel their jobs are more interesting and that they have more autonomy than before. Reed (1995) argues that under post-bureaucratic forms of control, a bifurcation emerges between strategic and operational levels of decision-making, with a process of 'decentralized centralization' dominating at all organizational levels. A framework of more extensive and intensive financial and informational control is put in place which closely monitors and regulates the actual exercise of delegated authority by 'front-line' staff.

\subsection{Measuring trust}

We now turn our attention to the workplace and consider questions of supervisory trust. The measure of trust is based on three direct questions concerning trust in the supervisor's competencies and benevolence. Following traditional leadership theories (e.g. Bass, 1985; Burns, 1978; Fiedler, 1967; Fox, 1974), competence is divided into two dimensions: trust in the supervisor's competence to lead people and competence to manage things. The distinction between competence-based trust and trust in benevolence (intentions), then, draws on Nooteboom's (2002) theory, which is supported by the qualitative data collected for this study (theme interviews conducted before the survey and survey respondents' written feedback on the questionnaire).

Figure 3. How much do you trust your supervisor's competence in managing people and managing things, and how much do you trust his/her benevolence?

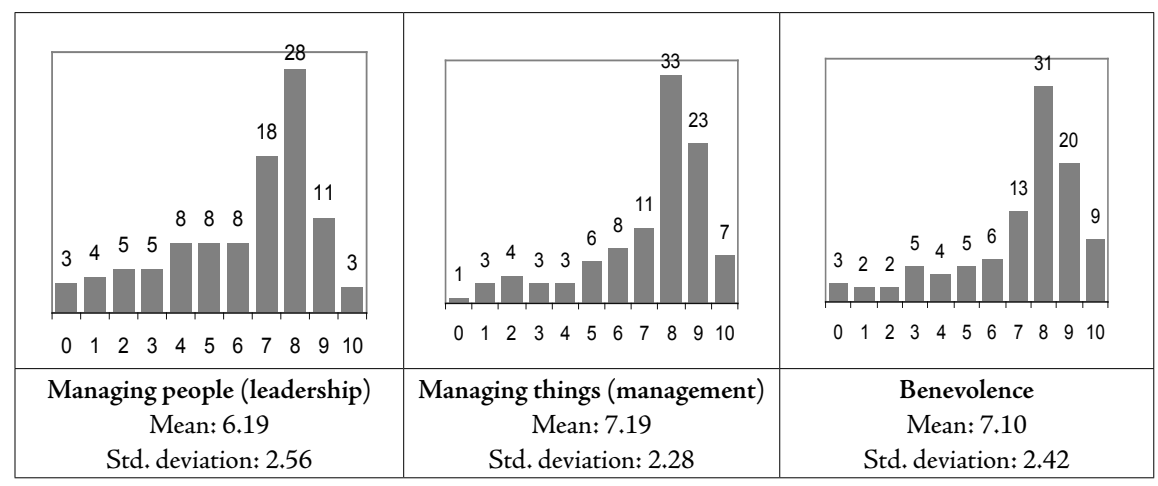

$(0=$ no trust $\ldots 10=$ complete trust $)$. Frequencies $(\%)$, means and standard deviations. 
Figure 3 shows that state employees' trust in their supervisors' leadership skills is lower (mean 6.19) than the corresponding trust scores for managing things and benevolence. This result can be interpreted as representing the heritage of bureaucracy, where promotions were based on seniority and professional competence. Today, however, increasing emphasis is placed on people management skills. Nevertheless, not all employees have embraced and accepted the 'new meritocracy' (Sennett 2006), as is clear from the following quotation from a survey respondent:

The senior management of [our] expert organization is incompetent. Many of our great leaders don't even have a doctoral degree, which is a basic requirement for an independent researcher just about anywhere. So how can these people be expected to understand the creative and innovative aspects of the researcher's job? (...) 'A good character' goes before all other competencies. You just have to be one of the good guys, that counts more than all your qualifications put together. Administration is based on the use of outside consultants who spread their flashy management doctrines without even translating them into Finnish. (...) If someone in our organization today were to discover gunpowder, development would be halted immediately because it is not in line with our strategy.

The distributions of the different dimensions of trust are skewed (in the direction of high trust). We therefore recoded the values into five groups of equal size (quintiles) to construct a sum variable for trust that is normally distributed, as required by regression analysis (Tabachnick and Fidell, 2001). The application of this criterion in the recoding minimized the loss of information.

Are there any statistical reasons to construct a sum variable that would capture the three dimensional nature of trust in a supervisor? Let us first look at the correlations between the different components of trust. According to the correlation analysis presented in Table 1, the two competence types (managing people and things) correlate positively with each other as well as with trust in benevolence. All correlation coefficients are statistically significant and quite strong.

Table 1. Correlations between the three dimensions of trust in supervisor

\begin{tabular}{|l|c|c|c|}
\hline & Managing people & Managing things & Benevolence \\
\hline Managing people & 1 & $.55^{\star *}$ & $.61^{\star *}$ \\
\hline Managing things & $.55^{\star *}$ & 1 & $.51^{\star *}$ \\
\hline Benevolence & $.61^{\star *}$ & $.51^{\star *}$ & 1 \\
\hline
\end{tabular}

** $\mathrm{p}<.01$ 
The alpha reliability coefficient (Cronbach's $\alpha$ ) for the sum scale is 0.79 . This is higher than the recommended lower limit of acceptance, 0.70 (Cortina, 1993). Thus, the construction of a sum variable is justified. Its scale is $3-15$, mean 8.6, and standard deviation 3.1.

\subsection{Tracing the antecedents of trust}

We then traced factors related to level of trust by using OLS regression. There are dozens of potential independent variables that may have a statistical relationship with supervisory trust; the most significant of these variables are presented in Table 2. The research setting for the explorative regression analysis is illustrated in Figure 4.

Figure 4. Tracing antecedents of trust in supervisor. Research setting.

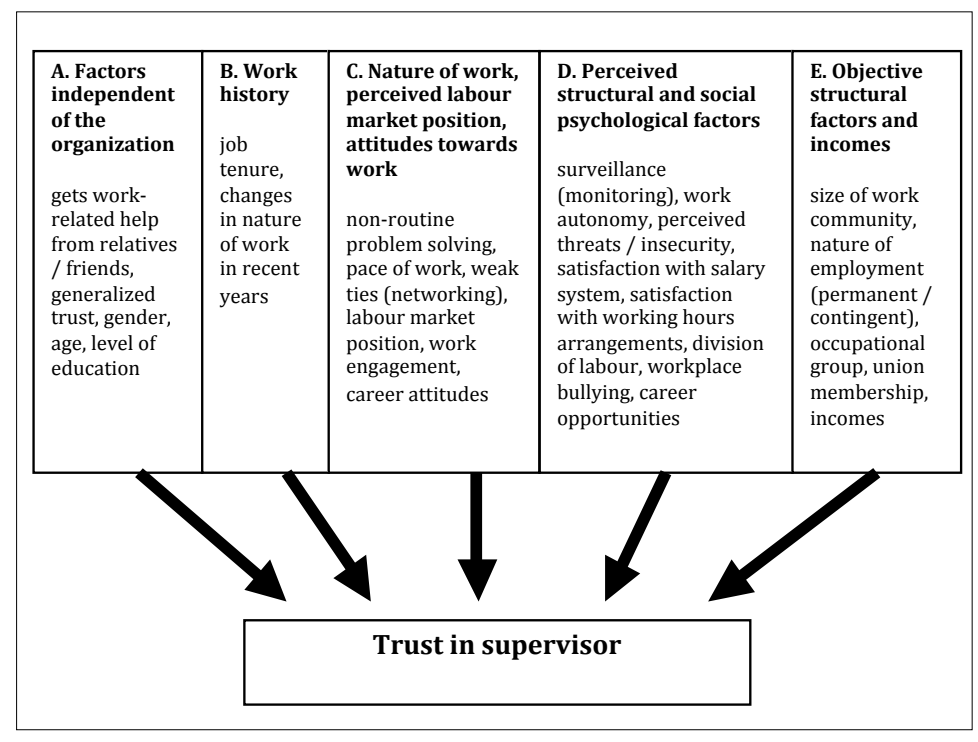

Potential predictors of trust are placed into five different categories in Figure 4. Many variables within these categories consist of items such as changes in the nature of work' and 'perceived threats', as outlined above. In addition, some variables are sum scales like 'work engagement' and 'satisfaction with working hours arrangements'. Altogether there are almost 100 different variables whose effects on trust we tested (directly or as an item of a sum variable). However, due to limited space we cannot present the details of every single variable. 
Table 2. Antecedents of trust in supervisor. OLS regression (stepwise).

\begin{tabular}{|l|c|c|c|}
\hline & $R_{a}^{2}$ & Beta & $T$ \\
\hline Supervisor monitors results of work & $40 \%$ & & \\
\hline Job autonomy (sum variable) & & $.29^{* * *}$ & 4.94 \\
\hline Has sometimes been bullied by supervisor & & $.20^{\star * *}$ & 4.68 \\
\hline Regular monthly income & & $-.17^{* * *}$ & -3.94 \\
\hline Supervisor monitors quality of work & & $-.14^{* *}$ & -3.22 \\
\hline Satisfied with salary system (sum variable) & & $.14^{*}$ & 2.42 \\
\hline Generalized trust (sum variable) & & $.13^{* *}$ & 2.81 \\
\hline Well-defined work role & & $.12^{* *}$ & 2.87 \\
\hline
\end{tabular}

${ }^{*} \mathrm{p}<.05 ;{ }^{* *} \mathrm{p}<.01 ;{ }^{* * *} \mathrm{p}<.001$

Table 2 shows the best model for predicting the level of trust in the supervisor. It includes eight antecedents of trust.

The model explains as much as $40 \%$ of the variance of trust (see adjusted $\mathrm{R}^{2}$ ). In contrast to the assumption that the monitoring of the results and quality of work would be negatively related to trust in the supervisor, these two items actually predict stronger trust! Kruglanski (1970) and Fox (1974) have suggested that an employee who is under almost constant monitoring might interpret the supervisor's surveillance as an indication of distrust in the employee, which in turn creates a sense of distrust in the supervisor.

We interpret that this unexpected result reflects the employees' belief that the supervisor is interested in and respects their contribution to the success of the unit or team. It is interesting that almost half of the respondents say that neither their results nor the quality of their work is monitored. This is consistent with the theory of post-bureaucratic organizations. Namely, it is possible that many supervisors do not really know how they should respond to the contradictory demands of strategic concentration and operational decentralization. This may further encourage a laissez faire attitude in leadership (Dingwall and Strangleman, 2004).

Although it may seem surprising to find a positive relation between trust and monitoring, the same result has in fact been reported in earlier studies. Edwards, Collinson and Reed (1998) found in their UK study that trust in management was associated with more, not fewer, strict controls. Their explanation was grounded in the disciplined worker thesis: if you are going to be exploited, you might as well be exploited well rather than badly. However, we found no evidence in our data to support this explanation. 
Like monitoring results and quality, job autonomy also increases trust in the supervisor. ${ }^{2}$ This can be explained by the social exchange theory (Blau, 1964; Fox, 1974). This theory states that the autonomy granted to them is perceived by employees as a gesture of trust by management - they rely on me to do my job responsibly' - to which the employee reciprocates with a similar attitude: i.e. by trusting management (cf. Gould-Williams and Davies, 2005). Although the organizations included in this study used to be Weberian bureaucracies, their organizational culture is characterized by a long tradition of professional autonomy. In other words, the recent increase in job autonomy can be seen as a continuum rather than a break.

What about the other antecedents of trust included in our explanatory model? Satisfaction with the pay system, which predicts trust, can be seen as implying reciprocal social exchange. ${ }^{3}$ No surprise here. Satisfaction with pay implies a perception of distributive justice, which fosters the development of reciprocity (Colquitt et alii, 2005; Homans, 1958). The fact that lower incomes predict higher trust seems very odd. However, the statistically significant relationship disappears if respondents' occupational status is controlled. We should bear in mind that in the model used satisfaction with the pay system is also controlled. The negative correlation seen between trust and bullying is no surprise, either. Being bullied by your supervisor is bound to affect your trust in him/her.

Supervisory trust is also predicted by generalized trust. The measure of generalized trust was adopted from the European Social Survey $(2007 / 2008){ }^{4}$ Generalized trust - which according to the ESS is very high among Finns - describes an individual's propensity to trust other people. It is thus interpreted as an independent factor from the organization and supervisor, although it is of course possible to think that the causal relationship is reversed i.e. work organizations function as 'secondary associations' (Putnam et alii, 1993) - generating trust in strangers at the societal level.

\footnotetext{
2 Job autonomy was examined by asking the respondents how much influence they have over (1) their job description, (2) the order of job tasks, (3) the pace of work, (4) work methods, (5) the distribution of assignments, (6) the choice of co-workers, and (7) the purchase of equipment and tools. The preset response options were: 1 = none, $2=$ some, $3=$ quite a lot, $4=$ a lot. Cronbach's $\alpha 0.79$.

3 Satisfaction with the salary system was assessed by asking the respondents: 'How satisfied are you with...' (1) the clarity of how your pay is determined (2) the balance between pay and job demands, (3) the dependence of your pay on performance, and (4) the fairness of your pay. The preset response options were: 1 = very unsatisfied, 2 = quite unsatisfied, 3 = neither unsatisfied nor satisfied, 4 = quite satisfied, 5 = very satisfied. Cronbach's $\alpha 0.92$.

4 Generalized trust was measured with the following three questions rated on a scale from 0 to 10: (1) Generally speaking, would you say that most people can be trusted, or that you can't be too careful? (2) Do you think that most people would try to take advantage of you if they got the chance, or would they try to be fair? (3) Would you say that most of the time people try to be helpful or that they are mostly looking out for themselves? Cronbach's $\alpha 0.84$.
} 
Finally, a well-defined work role is positively associated with trust in the supervisor. Clarity of work role was assessed by asking the respondents how well other people in the workplace were aware of the respondent's daily job tasks. Many employees believe it is the supervisor's job to create a division of labor in which work roles and responsibilities are clearly defined. Again, it is suggested that a poorly known job description generates a feeling that one is not an important link in the chain.

\section{Summary and discussion}

As the case of Finnish state administration goes to show, the development of managerial coordination in the public sector has had contradictory consequences. Decision-making has been decentralized, but at the same time economic power remains very much concentrated. In line with this trend, formalized procedures such as TQM, 'balanced score card' and other metrics adopted from the private sector have been introduced to the state administration.

Secondly, there are indications of a tendency to strengthen the market form of employment relations. Examples include the increased use of contingent employment (i.e. numerical flexibility) and different kinds of performance incentives. Third, organizations are trying to improve their knowledge management capabilities by strengthening employees' trust and commitment.

According to Adler (2001, p. 228), the efficacy of trust for knowledge management and the likelihood of its growth over time are maximized if: (a) trust is balanced by hierarchical rules to ensure stability and equity, (b) trust is balanced by market competition to ensure flexibility and opportunity, and (c) trust is modern and reflective rather than traditionalistic and 'blind'. Reflective trust, for Adler (ibidem, pp. 226-227), is derived from open dialogue among peers.

Hodson (2005) has observed that predictability is essential for the establishment of trust between employees and management. In a similar vein, Leana and van Buren (1999) suggest that the development of an organization's social capital requires time and stable employment. Because organizational social capital is built over time but can be quickly destroyed by such trust-breaking behavior as violating a psychological contract, a long- rather than short-term orientation in employee relations should be the norm.

Nevertheless, for most scholars bureaucracy and hierarchical control are undesirable things - 'evils of blind routine' (Sennett, 1998, p. 9). The mainstream assumes that control automatically implies mistrust. However, when the results 
of this study are reflected in relation to these different kinds of discourses, it seems that the mainstream assumptions should be re-evaluated. It is misleading to view trust and control as opposite ends of the spectrum.

In this article we have shown that many characteristics related to traditional bureaucracy - and lost with de-bureaucratization - such as well-defined work roles and 'assertive' leadership, are important to the formation of trust. This is a paradox because the post-bureaucratic model of organizing work per se is more dependent on trust (self-managed teams, functional flexibility, etc.) than Weberian bureaucracy based on formal rather than informal mechanisms of coordination.

There is a clear need for more research on how civil servants and other public sector employees adapt to the new post-bureaucratic environment. In this study we have focused on well-educated knowledge workers in selected parts of Finland's state administration. Concentrating on municipal workers, for example, could provide a different picture. Thus we need comprehensive surveys that adequately represent all kinds of public sector organizations. We also need to combine surveys with qualitative data, an approach we have found useful. Of course, all research settings have pros and cons. We are aware of the fact that the development of trust is a dynamic process in which time is a significant parameter. Therefore, the cross sectional research setting used in this study has more weaknesses than, for example, panel studies.

What is the main lesson to be learned from our results? Public sector reforms have often violated trust between employees and representatives of the employer. Clearly, this has had a demoralizing effect on employee relations. Should we hark back to bureaucracies? No, there is no turning back to earlier times. However, if we want to ensure staff commitment and organizational effectiveness in the public sector, then we had better learn how to combine trust with flexibility.

\section{Acknowledgements}

Jaakko Koivumäki would like to thank Professor Sarah Vickerstaff and Dr. Tim Strangleman from the University of Kent in Canterbury and Elina Koivumäki for support. Both authors gratefully acknowledge the financial support received from the Academy of Finland. 


\section{References}

Adler, P. (2001), «Market, hierarchy, and trust: the knowledge economy and the future of capitalism», Organization Science, Vol. 12 No. 2, pp. 215-234.

Alvesson, M. and Thompson, P. (2004), «Post-bureaucracy?», in Ackroyd, S.; Batt, R.; Tolbert, P. and Thompson, P. (Eds.), A Handbook of Work and Organization. Oxford University Press, Oxford, pp. 485-507.

Atrinson, P. and Housley, W. (2003), Interactionism. An Essay in Sociological Amnesia, Sage, London.

Bass, B. (1985), Leadership and Performance beyond Expectations, Free Press, New York, NY.

Bauman, Z. (1990), Thinking Sociologically. An introduction for Everyone, Blackwell, Cambridge, Mass.

Bijlsma-Frankema, K. and Costa, A. (2005), «Understanding the trustcontrol nexus», International Sociology, Vol. 20 No. 3, pp. 259-282.

Blau, P. (1964), Exchange and Power in Social Life, John Wiley \& Sons, New York, NY.

Blom, R.; Melin, H. and PyöRiä, P. (2002), «Social contradictions in informational capitalism: the case of Finnish wage earners and their labor market situation», The Information Society: An International Journal, Vol. 18 No. 5, pp. 333-343.

Blomqvist, K. (1997), «The many faces of trust», Scandinavian Journal of Management, Vol. 13 No. 3, pp. 271-286.

Bryman, A. (1992), «Quantitative and qualitative research: Further reflections on their integration», in Brannen, J. (ed.), Mixing Methods: Qualitative and Quantitative Research, Avebury, Aldershot, pp. 57-80.

Burns, J. (1978), Leadership, Harper \& Row, New York, NY.

Coleman, J. (1990), Foundations of Social Theory, The Belknap Press of Harvard University Press, Cambridge, MA.

Colquitt, J;; Greenberg, J. and Zapata-Phelan, C. (2005), «What is organizational justice? A historical overview», in Greenberg, J. and ColquitT, J. (eds.), Handbook of Organizational Justice, Lawrence Erlbaum Associates, Mahwah, NJ, pp. 3-56.

Cortina, J. (1993), «What is coefficient alpha? An examination of theory and applications», Journal of Applied Psychology, Vol. 78 No. 1, pp. 98-104.

Cummings, L. and Bromiley, P. (1996), «The organizational trust inventory (OTI): development and validation», in Kramer, R. and Tyler, T. (eds.), Trust in Organizations. Frontiers of Theory and Research, Sage, Thousand Oaks, pp. 302-330. 
Deci, E; Connell, J. and Ryan, R. (1989), «Self-determination in a work organization», Journal of Applied Psychology, Vol. 74 No. 4, pp. 580-590.

Den Hartog, D. (2003), «Trusting others in organizations: leaders, management and co-workers», in Noотевоом, B. and Six, F. (eds.), The Trust Process in Organizations. Empirical Studies of the Determinants and the Process of Trust Development, Edward Elgar, Cheltenham, pp. 125-146.

Dingwall, R. and Strangleman, T. (2004), «Organizational cultures in the public services», in Ferlie, E*; Lynn, L. Jr. and Pollitt, C. (Eds.), The Oxford Handbook of Public Management, Oxford University Press, Oxford, pp. 468-490.

Du Gay, P. (2000), In Praise of Bureaucracy. Weber, Organization, Ethics, Sage, London.

Edwards, P; Collinson, M. and Rees, C. (1998), «The determinants of employee responses to total quality management: six case studies», Organization Studies, Vol. 19 No. 3, pp. 449-457.

European Social Survey (2007/2008), European Foundation for the Improvement of Living and Working Conditions, Dublin.

Fiedler, F. (1967), A Theory of Leadership Effectiveness, McGraw-Hill, New York, NY.

Fiske, S. and Taylor, S. (1984), Social Cognition, Addison-Wesley, Reading, Mass.

Fox, A. (1974), Beyond Contract. Work, Power and Trust Relations, Faber and Faber, London.

Gould-Williams, J. and Davies, F+ (2005), «Using social exchange theory to predict the effects of HRM practice on employee outcomes: an analysis of public sector workers», Public Management Review, Vol. 7 No. 1, pp. 1-24.

Groth, L. (1999), Future Organizational Design. The Scope for the IT-based Enterprise, John Wiley \& Sons, Chichester.

Heckscher, C. and Donnellon, A. Eds (1994), The Post-Bureaucratic Organization. New Perspectives on Organizational Change, Sage, London.

Hodson, R. (2005), «Management behaviour as social capital: a systematic analysis of organizational ethnographies», British Journal of Industrial Relations, Vol. 43 No. 1, pp. 41-65.

Homans, G. (1958), «Social behavior as exchange», The American Journal of Sociology, Vol. 63 No. 6, pp. 597-606.

Hood, C. (1996), «Exploring variations in public management reform of the 1980s», in Bekke, H*; Perry, J. and Toonen, T. (eds.), Civil Service Systems 
in Comparative Perspective, Indiana University Press, Bloomington and Indianapolis, pp. 268-287.

KRUglanski, A. (1970), «Attributing trustworthiness in supervisor-worker relations», Journal of Experimental Psychology, Vol. 6, No. 3, pp. 214-232.

Leana, C. and van Buren, H. (1999), «Organizational social capital and employment practices», Academy of Management Review, Vol. 24 No. 3, pp. 538-555.

Lento, A-M. and Sutela, H. (2009), Three Decades of Working Conditions. Findings of Finnish Quality of Work Life Surveys 1977-2008, Statistics Finland, Helsinki.

Lewis, D. and Weigert, A. (1985), «Trust as social reality», Social Forces, Vol. 63 No. 4, pp. 967-985.

Mills, C.W. (1959), The Sociological Imagination, Oxford University Press, Oxford.

Nahapiet, J. and Ghoshal, S. (1998), «Social capital, intellectual capital, and the organizational advantage», Academy of Management Review, Vol. 23 No. 2, pp. 242-266.

Naschold, F. (1996). New Frontiers in Public Sector Management. Trends and issues in State and Local Government in Europe, de Gruyter, Berlin.

Noотевоом, B. (2002), Trust. Forms, Foundations, Functions, Failures and Figures, Edward Elgar, Cheltenham.

OECD (2000), Government of the Future, OECD, Paris.

OECD (2010), Economic Survey of Finland, 2010, OECD, Paris.

Pollitt, C. and Bouckaert, G. (2004), Public Management Reform. A Comparative Analysis, $2^{\text {nd }}$ Edition, Oxford University Press, Oxford.

Putnam, R.; Leonardi, R. and Nanetti, R. (1993), Making Democracy Work.

Civic Traditions in Modern Italy, Princeton University Press, New Jersey, NJ.

Pyörï̈, P. (2007a), «Informal organizational culture: the foundation of knowledge workers' performance», Journal of Knowledge Management, Vol. 11 No. 3, pp. 16-30.

Pyörï̈, P. (2007b), Understanding Work in the Age of Information. The Finnish Model of an Information Society, VDM Verlag Dr. Müller, Saarbrücken.

REeD, M. (1995), «Managing quality and organizational politics: TQM as a governmental technology», in Kirkpatrick, I. and Lucio, M. (eds.), The Politics of Quality in the Public Sector. The Management of Change, Routledge, London, pp. 44-64.

Rousseau, D.M. (1995), Psychological Contracts in Organizations. Understanding Written and Unwritten Aagreements, Sage, Thousand Oaks, CA. 
Schienstock, G. (2007), «From path dependency to path creation: Finland on its way to the knowledge-based economy», Current Sociology, Vol. 55 No. 1, pp. 92-109.

Sennett, R. (1998), The Corrosion of Character. The Personal Consequences of Work in the New Capitalism, W.W. Norton \& Company, New York, NY.

Sennett, R. (2006), The Culture of the New Capitalism, Yale University Press, New Haven, Conn.

Tаваснnick, B. and Fidell S. (2001), Using Multivariate Statistics, Allyn and Bacon, Boston.

Tashakkori, A. and Teddie, C. (1998), Mixed Methodology: Combining Qualitative and Quantitative Approaches. Applied Social Research Methods Series Vol. 46, Sage, London.

Temmes, M. (1998), «Finland and new public management», International Review of Administrative Sciences, Vol. 64 No. 4, pp. 441-456.

Tinli, M. (2008), Ministers as Strategic Political Leaders? Strategic Political Steering After NPM Reforms in Finland, Acta Politica 34, Department of Political Science, University of Helsinki, Helsinki.

Weber, M. (1978), Economy and Society. An Outline of Interpretive Sociology, University of California Press, Berkeley.

Wittek, R. and van de Bunt, G.G. (2004), «Post-bureaucratic governance, informal network and oppositional solidarity in organizations», The Netherlands' Journal of Social Sciences, Vol. 40 No. 3, pp. 295-319.

YIN, R.K. (1989), Case Study Research. Design and Methods. Revised Edition, Sage, London. 